\title{
Planos de educação no Brasil: projeções do sistema nacional de educação e suas variantes subnacionais
}

\section{Educational plans in Brazil: projections of the national system of education and its subnational variants}

\author{
Donaldo Bello de Souza ${ }^{1}$ \\ donaldosouza@hotmail.com \\ Marisa Ribeiro Teixeira Duarte ${ }^{2}$ \\ mmduarte@ufmg.br
}

\begin{abstract}
Resumo
O artigo discute o Plano Nacional de Educação (PNE) 2001-2010 e o processo de planejamento educacional nas esferas estadual, regional e municipal. Analisa dados secundários sobre Planos Estaduais de Educação (PEEs), Planos Regionais de Educação (PREs) e dos Planos Municipais de Educação (PMEs). Constata, a par da incipiência relativa à disseminação desses planos, a escassez de estudos teórico-empíricos que os enfocam, especialmente quanto aos seus efeitos na Educação Básica, tanto no âmbito nacional quanto subnacional. Ao concluir, expõe os desafios postos à democratização da Educação Básica no Brasil, o que coloca em questão, entre outros aspectos, a pertinência e a exequibilidade do planejamento educacional levado a efeito nas últimas décadas no país, em âmbito nacional e subnacional, especialmente em termos das metas proclamadas.
\end{abstract}

Palavras-chave: Plano Nacional de Educação; Planos Estaduais de Educação; Planos Regionais de Educação; Planos Municipais de Educação, democratização da educação.

\footnotetext{
Abstract

The article discusses the National Education Plan (NEP) from 2001 to 2011 and the process of educational planning at the state, regional and municipal levels. The study analyzed secondary data on State Education Plans (PEEs), Regional Education Plans (SRP) and the Municipal Education Plans (SMEs). Notes, alongside the incipience concerning the dissemination of these plans, as the shortage of theoretical-empirical studies that focus, in particular about its effect of both state and municipal levels. Upon completion exposes the challenges posed to the democratization of basic education which puts into question, among other aspects, the relevance and feasibility of educational planning undertaken in the last

1 Doutor em Educação pela Universidade Federal do Rio de Janeiro (UFRJ), com Pós-Doutorado em Política e Administração Educacional pela Faculdade de Psicologia e de Ciências da Educação (FPCE) da Universidade de Lisboa (UL). Professor Associado no Departamento de Políticas Públicas, Avaliação e Gestão da Educação (DEPAG) na Faculdade de Educação da Universidade do Estado do Rio de Janeiro (UERJ).

2 Doutora em Educação pela Universidade Federal Fluminense (UFF), com Pós-Doutorado junto ao Groupe Interdisciplinaire de Recherche sur la Socialisation, I'Education et la Formation da Université Catholique de Louvain. Professora Associada no Departamento de Administração Escolar (DAE) e Pesquisadora no Programa de Pós-Graduação em Educação da Faculdade de Educação da Universidade Federal de Minas Gerais (UFMG).
} 
few decades in this country, in national and subnational spheres, especially in terms of the goals proclaimed.

Key-words: National Education Plan; State Educational Plans; Regional Educational Plans; Municipal Educational Plans; democratization of the education.

\section{Introdução}

É possível afirmar que os primeiros Planos Nacionais de Educação (PNEs), elaborados ainda na década de 1930, no Brasil, estiveram marcados pelas tentativas de regulamentar procedimentos e o uso de recursos financeiros públicos na área da educação, subjazendo aos enunciados da política educacional do período tentativas de capturar as práticas políticas e sociais aos ditames da ciência. O plano como lei, sua abrangência nacional e uniformidade de procedimentos para todo o território constituíram elementos essenciais ao projeto nacional desenvolvimentista, estatalmente orientado por vertentes autoritárias. A partir dos idos de 1960 e, sobretudo, no período da ditadura (1964-1984), a submissão do planejamento educacional às diretrizes do desenvolvimentismo econômico, que se projetava, foi legitimada pela contraposição entre o planejamento dos experts versus a ação assistemática ou interessada dos políticos.

Com a Constituição Federal (CF) de 1988 (BRASIL, 1988) fez-se ressurgir a ideia de um PNE de longo prazo (inicialmente plurianual), com força de lei, com o objetivo de articulação sistêmica e voltado para conferir estabilidade às iniciativas governamentais e à aplicação de recursos na área de educação, orientação esta reiterada na Lei de Diretrizes e Bases da Educação Nacional (LDBEN) nำ 9.394, de 20 de dezembro de 1996 (BRASIL, 1996b). Esta lei incumbiu a União de elaborar o PNE em colaboração com os Estados e os Municípios (inc. I, art. 9º). Em 2009, por intermédio da Emenda Constitucional (EC) nº 59, de 11 de novembro de 2009 (BRASIL, 2009), nova redação do texto constitucional estabelece a duração do PNE, os princípios que devem presidir sua elaboração e as finalidades pretendidas (art. 214).

A última versão promulgada do PNE (I PNE) abrangeu o decênio 2001-2010 (BRASIL, 2001), enquanto aquela que poderia ser considerada a mais recente (II PNE) ainda se encontra ${ }^{3}$ em processo de trâmite no âmbito do Poder Legislativo federal (BRASIL, 2010). Embora relacionada ao decênio 2011-2020, o novo PNE, curiosamente, já perfez seu terceiro ano de inexistência legal ${ }^{4}$.

${ }^{3}$ Com referência ao mês e ano de elaboração deste artigo (set. 2013).

${ }^{4}$ A versão do II PNE (2011-2020), que consta no PL no 8.035, de 20 de dezembro de 2010 (BRASIL, 2010), veio a ser encaminhada pelo Poder Executivo ao Congresso Nacional nesta mesma data, tendo sido votado 
No presente artigo efetuamos análise do contexto de formulação e do conteúdo do I PNE 2001-2010, isto por intermédio de sua comparação à proposta apresentada pelo Fórum Nacional em Defesa da Escola Pública (FNDEP), especialmente quanto às ênfases de ação governamental postas no campo da Educação Básica, com vistas ao exame da sua repercussão nas esferas estaduais, regionais e municipais, respectivamente em termos da formulação e implantação dos Planos Estaduais de Educação (PEEs), dos Planos Regionais de Educação (PREs) e dos Planos Municipais de Educação (PMEs) ${ }^{5}$, de modo a discutir a disseminação e os impactos desses planos no país, tomando por base estudos teórico-empíricos pertinentes ${ }^{6}$.

\section{Propostas para o PNE 2001-2010}

Em fevereiro de 1998, duas propostas para o PNE 2001-2010 chegaram ao Congresso Nacional. A primeira, consubstanciada no documento conhecido como o PNE da Sociedade Brasileira, reivindicava o fortalecimento da escola pública estatal e a plena democratização da gestão educacional como eixo do esforço para universalizar a educação básica (VALENTE; ROMANO, 2002), tendo sido elaborada pelo FNDEP (composto por educadores, profissionais, militantes ligados à área da educação, estudantes, etc.), no âmbito dos I e || Congressos Nacionais de Educação (CONEDS), realizados em Belo Horizonte - o primeiro em julho-agosto de 1996, enquanto que o segundo em novembro de 1997. Esses congressos foram considerados como espaços políticos de luta, resultado da

pela Comissão Especial da Câmara dos Deputados (CEC), à qual estava subordinado, somente um ano e meio após, em 13 de junho de 2012. Em sequência à votação simbólica do Relatório Substitutivo final do PL na Comissão de Constituição e Justiça e de Cidadania da Câmara (CCJC), em 16 de outubro de 2012, seu encaminhamento ao Senado Federal, pela Mesa Diretora da Câmara dos Deputados, ocorreu em 25 de outubro deste mesmo ano, onde, desde então, aguarda sua avaliação em decisão terminativa ou, mediante assinatura de requerimento pelos senadores, por meio de discussão e votação no Plenário. Considerando o término da vigência do I PNE, ocorrido em 2010, mesmo que a sua lei ainda não tenha sido revogada - Lei 10.172, de 09 de janeiro de 2001 (BRASIL, 2001) -, é possível afirmar que o país se encontra desde então sem um novo plano de educação de abrangência nacional.

${ }^{5}$ Cumpre destacar que além desses planos (PEEs, PREs e PMEs), as repercussões de um PNE também poderiam se fazer notar no Brasil na esfera distrital, nomeadamente em termos do Plano de Educação do Distrito Federal (PEDF), embora, segundo dados relativos ao ano de 2010, levantados pelo Observatório da Educação da ONG Ação Educativa, este território, até então, se encontrava sem o plano em questão. Disponível em:

http://www.observatoriodaeducacao.org.br/index.php?option=com content\&view=article\&id=993:mais - dametade-dos-estados-nao-possui-plano-estadual-de-educacao\&catid=48:sugestoes-de-pautas\&ltemid=98> Acesso em: 11 fev. 2013.

6 Este artigo contou com a colaboração do bolsista do Programa Institucional de Iniciação Científica da Universidade do Estado do Rio de Janeiro (PIBIC/UERJ), Gustavo José Albino de Sousa, que, ao longo dos anos 2011-2013, inventariou, classificou e resumiu cerca de 150 referências sobre os planos de educação no Brasil, entre dissertações e teses, artigos em periódicos, trabalhos em Anais de eventos científicos, além de livros no todo e partes de livros, com recorte temporal correspondente ao período 1996-2010, viabilizando o balanço sobre a produção teórico-empírica relativa aos PEEs, PREs e PMEs, a seguir levada a efeito (cf. SOUSA, 2012; SOUZA; SOUSA, 2013). 
conjunção do diálogo entre entidades educacionais e associações profissionais (CURY, 1998; OLIVEIRA, 2002).

Um segundo projeto, denominado Proposta do Executivo ao Congresso Nacional, foi elaborado sobre a égide do então Ministério da Educação (MEC), tendo contado com a interlocução do Conselho Nacional de Educação (CNE), do Conselho dos Secretários Estaduais de Educação (CONSED) e da União Nacional dos Dirigentes Municipais de Educação (UNDIME). A literatura em política educacional que o examinou o qualifica como expondo uma racionalidade tipicamente administrativa (BEISIEGEL, 1999) e economicista (DAVIES, 2001), coesa às propostas de reforma neoliberal do Estado brasileiro então em curso (PERONI, 2003; VIEIRA; FARIAS, 2007), e em conformidade ao receituário internacional emanado pelos órgãos multilaterais de financiamento e de cooperação técnica (SOUZA; FARIA, 2003).

Apesar destas duas propostas serem consideradas como formulações diametralmente opostas em relação às concepções, diretrizes e metas que as definem (CURY, 1998; DAVIES, 2002), a tramitação de ambas no Congresso Nacional pode ser vista como reveladora dos efeitos produzidos pela democratização do país. Os dois planos projetaram concepções diferenciadas para a produção de mudanças no sistema educacional do país, fruto da reorganização dos partidos políticos, movimentos sociais e entidades de classes anteriormente excluídos dos processos de formulação. Por conseguinte, diferenciam-se em relação à forma como questões se destacam entre os atores formuladores de políticas públicas em educação e, a um só tempo, geram alternativas de solução, cujas tensões e confrontos parlamentares, conforme nos fala Oliveira (2009), transcenderam, no caso do I PNE, à sua tramitação, ampliando-se para o conjunto das políticas educacionais então vigentes no país.

O texto do PNE 2001-2010 aprovado, em 2001, pelo Congresso Nacional - Lei 10.172, de 9 de janeiro de 2001 (BRASIL, 2001) -, consagrou a maior parte da proposta enviada pelo Poder Executivo. Seu Projeto de Lei ( $P L)$ foi encaminhado ao Poder Legislativo em resposta à proposta apresentada pelo FNDEP que já iniciara a sua tramitação. Era composto pelo diagnóstico referente a cada nível, etapa e modalidade da educação nacional, pelas respectivas diretrizes e metas, tratando da formação docente, do financiamento e da gestão, além do detalhamento do seu acompanhamento e avaliação. No entanto, a ênfase posta nesses dois projetos à atuação dos entes federados no campo educacional continha diferenças significativas em relação à organização e funcionamento do sistema educacional brasileiro.

Genericamente, a proposta encaminhada pelo executivo proclamava que todas as 
crianças, jovens e adultos tivessem condições de acesso e permanência em escolas públicas do Brasil até 2011. Os princípios e diretrizes assumidos em Jontien7 receberam tradução ao longo do texto do PNE apresentado pelo poder executivo, e a ênfase de ação foi posta na expansão do atendimento da etapa obrigatória da Educação Básica, que constituía, à época, direito público subjetivo: o Ensino Fundamental.

O PNE 2001-2010 contou com dois mecanismos operacionais de suas diretrizes. Por um lado, o Fundo de Manutenção e Desenvolvimento do Ensino Fundamental e de Valorização do Magistério (FUNDEF), fundo contábil que veio a induzir a expansão da matrícula mediante a redistribuição dos recursos de Estados e Municípios (DUARTE, 2005) e, por outro, a difusão do Sistema Nacional de Avaliação da Educação Básica (SAEB), que constituía o segundo eixo de operacionalização das diretrizes postas no PNE. Neste objetivos de melhoria da qualidade da educação passam, paulatinamente, a significar melhoria do rendimento do estudante aferido pelos testes nacionais o que significava a introdução de instrumento de avaliação das escolas e dos sistemas de ensino.

Ao findar o período de vigência do I PNE, verificou-se o decréscimo de $2 \%$ na matrícula em toda a Educação Básica, o que equivale ao quantitativo de 1,030.563. Este fenômeno é analisado como decorrência da regularização do fluxo de alunos, especialmente no Ensino Fundamental (BRASIL, 2010, p. 2), devendo-se, entretanto, atentar para o fato de que também expressa a ênfase posta a partir deste período em buscar a gestão eficiente do sistema educacional em contraposição a investimento na sua infraestrutura. Para o mesmo período verificou-se crescimento na média nacional de proficiência em língua portuguesa e matemática dos alunos do ensino fundamental ( $1^{\circ}$ ao 9 ำ ano) e do ensino médio. Entretanto, os resultados médios acham-se bem aquém dos países com economia semelhante.

De acordo com Abicalil $(2005,2007)$, para que a plenitude de metas, ações e políticas deste plano fossem alcançadas seria de fundamental importância a realização de um esforço coletivo no que concerne à cooperação entre os entes federados e a prevista colaboração entre os seus respectivos sistemas de ensino. No entanto, o esforço coletivo de cooperação entre os entes federados no PNE 2001-2011 significava obter ganhos de eficiência e/ou eficácia na aplicação dos recursos tributários dos entes subnacionais vinculados à educação. Prova disto é que todos os nove vetos impostos pela Presidência

\footnotetext{
7 A Conferência de Jomtien, cujo documento final, assinado pelo Brasil em 1990, viria a ser conhecido como Declaração de Jomtien (CONFERÊNCIA MUNDIAL SOBRE EDUCAÇÃO PARA TODOS, 1998) - foi patrocinada pelo Banco Mundial (BM) em conjunto com o Programa das Nações Unidas para 0 Desenvolvimento (PNUD), o Programa das Nações Unidas para a Educação, Ciência e a Cultura (UNESCO) e o Fundo das Nações Unidas para a Infância (UNICEF) (DE TOMMASI, 1996, FONSECA, 1998).
} 
da República foram nos dispositivos relativos ao financiamento da educação, em particular às metas que previam aumento dos gastos da União (DAVIES, 2002; MENDONÇA, 2002). Para Cury (2011), o texto aprovado resultou em um plano sem a devida sustentação social, mas também econômico-financeira. A inexistência de novos aportes de recursos financeiros, por sua vez, contribuiu para que Estados e Municípios fossem lenientes na produção dos seus respectivos planos de educação, implicando limitações de largo espectro quanto à obtenção de suas metas.

Em contraposição, o documento apresentado pelas entidades não governamentais, conhecido como documento da sociedade civil, considerava como central a expansão do financiamento da educação escolar pública e gratuita. Recursos públicos insuficientes era o diagnóstico que fundamentava a defesa de maiores investimentos para o alcance das metas de atendimento projetadas. Nesse documento a tradução efetuada do compromisso firmado em Jontien em relação ao direito à educação reporta ao conceito de Educação Básica como definido no texto constitucional aprovado em 1988: da Educação Infantil ao Ensino Médio. Desse modo, no plano conhecido como "da sociedade civil" ao termo qualidade social atribuía-se o significado de expansão da oferta e da infraestrutura das escolas, especialmente onde o acesso era precário: a educação infantil e o ensino médio.

Ao longo do processo de implementação do PNE 2001-2010, "ainda foram mantidos limites históricos no tocante à efetivação da articulação da União com os demais entes federados, em especial com os municípios" (AGUIAR, 2010, p. 717), o que equivale dizer que a não efetivação do regime de colaboração, ao lado dos problemas que marcaram a participação sociopolítica nos Estados e Municípios, em larga medida podem ser também tomados como causas do não cumprimento da maior parcela das metas previstas no plano em questão, uma vez que o seu desdobramento em PEEs e PMEs ocorreu à margem do esperado, portanto, fazendo-se notar em poucos territórios, contrariamente ao previsto na Lei $n^{0}$ 10.172/2001 (BRASIL, 2001), exprimindo o seu déficit de legitimidade político-social (MARTINS, 2011).

\section{Os Planos Estaduais de Educação}

Curiosamente, segundo dados concernentes ao levantamento realizado pelo Observatório da Educação da Organização Não Governamental (ONG) Ação Educativa8, em 2010 - último ano de vigência do PNE 2001-2010 -, se constata que apenas 42\% (11)

\footnotetext{
${ }^{8}$ Disponível em:

<http://www.observatoriodaeducacao.org.br/index.php?view=article\&id=995\%3Aacompanhe-a-situacao-doplano-de-educacao-de-cada-estado\&option=com_content\&ltemid=98> Acesso em: 11 fev. 2013.
} 
dos 26 Estados da federação possuíam PEEs, fazendo-se presente, apenas, nos seguintes territórios: pioneiramente, em Pernambuco, aprovado em 2002, e no Mato Grosso do Sul, aprovado em 2003; em Alagoas, na Bahia e Paraíba, aprovados em 2006, e no Tocantins, aprovado em 2007; sendo que, de modo relativamente tardio, no Amazonas, Goiás e Mato Grosso, aprovados em 2008; no Rio de Janeiro, aprovado em 2009, e, mais recentemente, no Pará, aprovado em 2010.

Com elevada defasagem de criação legal em relação à regulamentação do $\mathrm{PNE}$ 2001-2010 (BRASIL, 2011) - em termos médios, 5,6 anos -, cabe ainda destacar que: "A maioria dos planos já existentes nos Estados possui centenas de metas. É o caso de Mato Grosso (com 475 metas), Alagoas (que tem 329) e do Amazonas (com 306)"9, expondo certa correspondência ao PNE 2001-2010 na medida em que este se pautou em cerca de 295 metas. Estes elevados quantitativos de metas podem tornar inexequíveis tanto a implantação do plano, quanto propriamente o seu monitoramento e avaliação pelo poder público e/ou pela sociedade civil - que deveria ocorrer, prioritariamente, no âmbito, quer dos Conselhos Estaduais de Educação (CEEs), quer dos Fóruns Estaduais de Educação (FEEs).

Já o Amapá, Maranhão e Rondônia, também em 2010, ainda não haviam encaminhado seus PEEs à Assembléia Legislativa $(A L)$ correspondente, enquanto que os de Minas Gerais e de São Paulo aguardavam aprovação pela AL. Por outro lado, Estados como Paraná, Rio Grande do Sul, Santa Catarina e Roraima não vieram a ter seus PEEs aprovados, respectivamente, pela $A L$ (os dois primeiros Estados), pela Casa Civil e pelo CEE. Não possuíam PEE os Estados do Piauí, Rio Grande do Norte, Roraima e, em termos distritais, o Distrito Federal (DF), enquanto que o Acre, Ceará, Espírito Santo e Sergipe, apesar de não terem elaborado seus PEEs em sintonia ao PNE, vinham estabelecendo parâmetros para o planejamento local da educação por meio de instrumentos internos à Secretaria Estadual de Educação (SEE), a exemplo dos planos estratégicos e dos planos estaduais de desenvolvimento da educação ${ }^{10}$.

De um modo ou de outro, o cenário até aqui traçado expressa a pouca importância atribuída por estes entes federados aos planos de educação o que, conforme acima aludido, igualmente afeta o planejamento na esfera municipal.

\footnotetext{
${ }^{9}$ Disponível em:

<http://www.observatorio daeducacao.org.br/index.php?view=article\&id=995\%3Aacompanhe-a-situacaodo-plano-de-educacao-de-cada-estado\&option=com_content\&Itemid=98> Acesso em: 11 fev. 2013.

10 Disponível em:

<http://www.observatoriodaeducacao.org.br/index.php?view=article\&id=995\%3Aacompanhe-a-situacao-doplano-de-educacao-de-cada-estado\&option=com_content\&ltemid=98> Acesso em: 11 fev. 2013.
} 
A um só tempo, se considerada a produção acadêmica na área da educação, é possível afirmar que pouco se sabe a respeito dos PEEs existentes, quer em termos do seu processo de elaboração, quer no que remete à sua perspectiva político-educacional, implantação, acompanhamento e avaliação, em especial.

Com base nos poucos estudos existentes (cf. SOUZA; SOUSA, 2012), é possível depreender que a questão fundamental revelada por pesquisas que tomaram os PEEs do país como alvo, publicadas no período 1996-2010, consiste na problemática de seu processo de formulação, em especial a participação sociopolítica estadual. Esses estudos atestam a fragilidade de práticas democrático-participativas ampliadas que respaldem a construção coletiva desses planos, desafio ainda longe de ser tomado como solúvel. Por exemplo, no Estado do Paraná e São Paulo, Arias (2007) e Dantas (2008), respectivamente, identificam, práticas democráticas de cunho meramente representativa em torno da elaboração do PE; em Alagoas, o exame de Souza (2007) sobre o processo de elaboração desse plano igualmente indicou baixa mobilização sociopolítica em torno da sua discussão e elaboração e, por fim, no Rio de Janeiro, Valle, Menezes e Vasconcelos (2012) chamam a atenção para o fato de que a elaboração e aprovação do PEE levou cerca de oito anos, principiando em 2001, concomitantemente ao ano de criação do IPNE 2001 2010, e concluído somente em 2009, um ano antes do término da vigência deste plano nacional.

Em síntese o foco dos estudos realizados dirigiu-se para o processo de elaboração dos PEEs, ou seja, para analisar que atores foram capazes de apresentar seus interesses e desse modo influenciar no conteúdo do documento. A conclusão reiterada de baixa participação revela que o modus operandi do planejamento educacional nos estados subnacionais não acolheu de forma eficaz e democrática intervenções de atores com capacidade de vocalização (exposição pública de seus interesses, valores, etc.) de interesses diferenciados, dos grupos no governo.

Tal panorama, caracterizado pela elevada taxa de abstinência dos Estados na elaboração dos seus PEEs, seja do ponto de vista legal, seja em termos de sua implementação real, incluída do seu acompanhamento e avaliação contribuiu tanto para o descumprimento das metas previstas no PNE 2001-2010, conforme anteriormente frisado. É passível de constatação no que tange ao PNE 2001-2010, a fragilidade do seu rebatimento em nível local, minguando a importância, em especial, dos PREs e PMEs. Essa ausência traz reflexos que se estendem, para a configuração cartorial de planos. Municipais. Por exemplo, a sua existência local, passando por uma elaboração não democrática, o documento produzido é meramente formal, à margem da sua 
implementação real.

\section{Os Planos Regionais de Educação}

O PRE não se trata de um plano no Brasil cuja disseminação se faz notar em larga escala, com ocorrência presumidamente inferior ao quantitativo de PEEs, consistindo, portanto, numa ação de planejamento que se pauta na divisão territorial administrativapolítica praticada por alguns Estados, de modo a atender demandas específicas e, ao mesmo tempo, relativamente comuns entre alguns Municípios.

Esta divisão administrativa dos territórios, realizada pela organização política do Estado, tende a fazer com que as regiões se imponham como realidades concretas, isto pala forma como as estatísticas oficiais as tratam e disponibilizam, e menos pelas particularidades de suas fronteiras (SOUZA; TORRES, 2003).

No caso do Brasil, pelo fato de os Municípios terem ascendido com a CF e 1988 (BRASIL, 1988) à condição de entes autônomos federados, novos desafios surgem para a cooperação intermunicipal, pois, face ao processo de descentralização da gestão dos serviços públicos, a colaboração no interior dessas regiões tende a diminuir os processos de regulação centralizados pelos Estados ou pela União (LACERDA, 2011).

Exemplo desse potencial democratizante da gestão pública no campo da educação - embora se reconheça sua dependência em relação às mediações sociopolíticas -, é revelada pela pesquisa de Munarim (1999; 2000), que enfocou o PRE 1991-1996 desenvolvido pela Secretaria Estadual de Educação (SEE) de Santa Catarina articuladamente a 19 localidades pertencentes à Associação dos Municípios da Região Serrana do Estado (AMRSE) que, curiosamente, até 2010, não possuía seu PEE ${ }^{11}$. Conforme sinalizado em nosso outro estudo (CALDERÓN; SOUZA, 2013), essas associações municipais em Santa Catarina são comuns (em 2006 totalizavam cerca de 21 unidades, aglutinando os 292 Municípios do Estado), "e existem como forma de impulsionar o desenvolvimento da região por meio da ajuda mútua, nos assuntos de interesse das administrações municipais" (PIEROZAN ${ }^{12}$, apud CALDERÓN; SOUZA, 2013, p. 200), o que

11 De acordo com dados relativos ao ano de 2010, levantados pelo Observatório da Educação da ONG Ação Educativa, a Secretaria Estadual de Educação (SEE) de Santa Catarina informou que a seis anos, de modo participativo, construiu uma proposta de PEE, mas que nunca veio a ser enviada para a Assembléia do Estado: "A informação é de que a Casa Civil considerou as propostas inviáveis". Disponível em: <http://www.observatoriodaeducacao.org.br/index. php?view=article\&id=995\%3Aacompanhe-a-situacaodo-plano-de-educacao-de-cada-estado\&option=com_content\&ltemid=98> Acesso em: 11 fev. 2013.

12 PIEROZAN, Sandra Simone Hopner. Um estudo dos conselhos municipais de educação, seus limites e possibilidades. Curitiba, 2006. 228 f. Dissertação (Mestrado em Educação) - Faculdade de Educação, Universidade Federal do Paraná, p. 154. 
pode favorecer, entre outras aspectos, a existência de PREs.

Para Munarim (1999; 2000), embora a ordem mundial aponte um modelo de descentralização contraditoriamente marcado por uma concentração de poder, o PRE examinado pode ser tomado enquanto experiência democratizante da gestão educacional na AMRSE, em especial se considerado o caráter histórico-autoritário das relações sociais que caracterizam aquela região do Estado de Santa Catarina.

Conclusivamente, apesar da escassez de informações sobre os PREs no país, seja do ponto de vista institucional, seja em teremos dos estudos acadêmicos que os tenham tomado por alvo de análise (cf. SOUZA; SOUSA, 2012), é importante ressaltar que esses planos somente podem vir a contribuir para a formulação de políticas públicas na área da educação caso suas ações objetivem intervenções nesta mesma escala, e não em nível local. Conforme postulado por Souza \& Torres (2003, p. 37), as análises regionais são passíveis de contribuir para a apreensão de "grandes diferenças - particularidades na escala nacional e entre as nações", cuja translação para a esfera local ainda continua a constituir-se desafio para a gestão pública no país.

\section{Os Planos Municipais de Educação}

A partir da CF 1988 (BRASIL, 1988), e até o ano de 2000, a divisão territorial do Brasil será sobremaneira aprofundada, criando-se cerca de 26\% (1.438) de todos os Municípios existentes em 2011 (5.565), processo que, por força dessa Carta Magna, veio a ser politicamente decidido e regulado pelos Estados, não mais, portanto, subordinado à União. Em larga medida, essas iniciativas irão envolver micro e pequenos Municípios, tipicamente com menos de dez mil habitantes (cerca de $74 \%$ dos Municípios criados naquele período), até que, em 1996, ou seja, oito anos após a promulgação da CF, ocorre a recentralização normativa da criação de Municípios para a esfera da União, pela via da EC $n^{\circ}$ 15, de 12 de setembro de 1996 (BRASIL, 1996a), resultando numa espécie de refreio da onda municipalista, cujas novas regras não se configurarão tão flexíveis quanto aquelas que vinham sendo praticadas pelos Estados (TOMIO, 2002).

Em outras palavras, os sistemas municipais de ensino deveriam constituir-se em organizações relativamente independentes e autônomas, cujas regulamentações e normas seriam previstas por seus próprios órgãos normativos, que considerariam, entretanto, em suas deliberações, o disposto na LDBEN, no PNE 2001-2010 e nas diretrizes nacionais processualmente emanadas do CNE. Isto é, a autonomia anunciada poderia tornar-se realidade, desde que não descumprisse a lei e as normas estabelecidas em âmbito 
federal ${ }^{13}$, entretanto, abrindo espaço, dentre outros aspectos, para a construção de instrumentos $^{14}$ específicos de gestão da educação local, como os PMEs.

No limiar da década de 1980, a ideia de formulação de um Plano de Educação irá atingir os Municípios de uma dupla forma: de um lado, no momento em que o I PNE 20012010 (BRASIL, 2001) veio a ser elaborado e, mais recentemente com o novo PNE, ainda transitando no Senado Federal ${ }^{15}$ - originalmente previsto para o decênio 2011-2020 (BRASIL.MEC.SE, 2010; BRASIL, 2010). Na atualidade, pelo menos em termos formais, o processo de formulação do PNE pressupõe a participação do conjunto da sociedade brasileira - incluindo-se, portanto, os espaços locais -, o que tem estimulado uma tendência local voltada à elaboração dos seus respectivos PMEs, com participação social mais ativa, fenômeno que carece de análises mais rigorosas.

Assim, os PMEs viriam a fazer parte integrante do conjunto de estratégias políticoeducacionais dos Municípios, de modo a que estas instâncias logrem gerir a educação com transparência e de modo coeso aos anseios locais, o que equivale afirmar, nas palavras de Saviani (1999, p. 134), que esta venha a ocorrer sob uma "racionalidade social" e não "financeira". Para Gadotti (2000, p. 172) a eficácia de um PME encontra-se diretamente dependente da participação dos "principais agentes de educação no Município sob a coordenação do Conselho Municipal de Educação, a partir do conhecimento das reais necessidades locais".

Trata-se, pois, da elaboração de um plano não redutível à esfera governamental, mas estatal, pois os seus objetivos "são da alçada do próprio município, não podendo estar descolados das aspirações da população e dos administradores municipais, o que não deve ser confundido com os interesses do governo em exercício, que na maior parte se estende por no máximo quatro anos enquanto o Plano Municipal de Educação tem duração de dez anos" (BRASIL.IBGE, 2012, p. 52).

\footnotetext{
13 Nesse processo, os Estados já tinham sido afetados por políticas de descentralização da gestão do ensino, uma vez que em 1961, com a promulgação da Lei n 4.024, de 20 de dezembro de 1961 (BRASIL, 1961), foram criados os sistemas estaduais de educação e seus respectivos Conselhos Estaduais de Educação (CEE). Mas somente dez anos após, com a Lei $\mathrm{n}^{\circ}$ 5.692, de 11 de agosto de 1971 (BRASIL, 1971), surgiu a primeira referência (art. 71) às atribuições que esses conselhos deveriam delegar aos CMEs (BORDIGNON, 2001), confirmando e expandindo o caráter normativo dos conselhos de educação no país e, ainda, facultando aos Municípios que possuíssem determinadas condições a constituição de seus próprios CMEs, órgãos que viriam a ter competências delegadas por seus respectivos CEEs (TEIXEIRA, 2004).

14 É importante destacar que a consideração dos planos de educação enquanto mero instrumento de gestão pode restringir sua compreensão e prática de construção social, portanto, despolitizá-lo, a exemplo de sua primeira manifestação explícita, em 1932, por época do Manifesto dos Pioneiros da Educação Nova, expressão, de acordo com Saviani (1998, p. 75) da "introdução da racionalidade científica no campo da educação".

15 Com referência ao mês e ano de elaboração deste artigo (set. 2013).
} 
Todavia, de acordo com dados da Pesquisa de Informações Básicas Municipais (MUNIC), realizada pelo Instituto Brasileiro de Geografia e Estatística (IBGE), relativos ao ano de 2011 (BRASIL.IBGE, 2012), dos 5.565 Municípios da federação, apenas cerca de $60,8 \%$ (3.384) declaram possuir seus planos locais, resultado do incremento de 4,4 pontos percentuais em relação ao quantitativo anteriormente identificado, em 2009 (BRASIL.IBGE, 2010), trazendo à vista a ausência deste plano, no mínimo, em 39,2\% das localidades do país.

Já do ponto de vista dos estudos teórico-empíricos que versam sobre os PMEs no Brasil, levantamento documental exaustivo realizado acerca da produção científica correlata, cobrindo o período 1996-2010 (cf. SOUZA; SOUSA, 2012), indica que apenas seis $(22,2 \%)$, das 27 unidades federadas, expõem exame científico de pelo menos um dos seus PMEs, a saber: Rio Grande do Sul, Paraná, Rio de Janeiro, Mato Grosso do Sul, Alagoas e Rio Grande do Norte, conforme a seguir apontado.

No âmbito do Rio Grande do Sul, os estudos de Drabach \& Miranda (2005), Assumpção (2006a; 2006b), Gheno, (2008) e Werle \& Barcellos (2008) enfatizam exemplos de sucesso e de problemas que marcam a formulação dos PMEs em variadas localidades do Estado. O trabalho de Drabach \& Miranda (2005), foca o processo de elaboração do PME de Santa Maria, Município da Região Centro-Oeste deste Estado, no período de 20042005. Os autores destacam o fato de que pela primeira vez na história desta localidade a população foi chamada a participar da elaboração de proposições educacionais. Mas, o estudo evidenciou que "a democracia representativa parece ter se sobreposto à democracia participativa" (DRABACH; MIRANDA, 2005, p. 13), pois a ocorrência de pouca discussão em torno das reais necessidades e anseios da comunidade local, e intensa prática de legitimação de idéias pré-estabelecidas, sem saber-se "se foram elaboradas coletivamente, ou se resumem o pensamento de professores e equipe diretiva [das escolas]" (id.).

Dois outros Municípios do Estado do Rio Grande do Sul, pertencentes à sua região norte, Novo Xingu e Vicente Dutra, foram enfocados por Assumpção (2006a; 2006b), também com o objetivo de examinar o momento e a forma de participação da comunidade local na elaboração dos seus respectivos PMEs. Os resultados apresentados sinalizam realidades diferenciadas: enquanto que em uma dessas localidades (não informada pelo autor) constata-se a existência de uma forma de planejamento participativo na qual "os atores definiram os rumos, estabeleceram horizontes, determinaram os objetivos, as metas e as estratégias, com base no diagnóstico apontado pelos próprios sujeitos." (ASSUMPÇÃO, 2006a, p. 140-141), na outra se observa um tipo de planejamento no qual "o exercício do poder, do mando, da centralidade falou mais alto que a participação dos 
sujeitos" (id.), à margem, portanto, da participação da sociedade civil e, no caso particular dos professores, "aquém dos sonhos e das esperanças de muitos deles" (id).

Por seu turno, a pesquisa de Gheno, (2008), que toma por objeto o PME de Esteio, Município da Região Metropolitana (RM) de Porto Alegre, também visando analisar a construção deste documento a partir da sua divulgação à comunidade e da participação social, identificou a inexistência de formas democráticas e participativas na sua estruturação. Para a capital do Estado, o Município de Porto Alegre, Werle \& Barcellos (2008) analisam o PME desde sua tramitação no legislativo e no CME local, considerando os atores envolvidos nos diferentes momentos desse processo, os discursos e visões de mundo manifestas. As autoras notam que este PME expõe uma série de problemas relativos à sua lógica de construção e ao paradigma discursivo que sustenta seu texto, estando marcado por uma "heterogeneidade entre metas e diretrizes, além de ocultar uma visão administrativa e ideológica das políticas em andamento" (WERLE; BARCELLOS, 2008, p. 540) ${ }^{16}$.

Ainda na Região Sul do país, observa-se a pesquisa de Santos (2004a; 2004b), que analisou a gestão da educação no Município de Araucária, Estado do Paraná, correspondente ao período 2001-2004, detendo-se na concepção de gestão democrática presente, em especial, no seu PME. O estudo revela que este plano se consubstanciou em meio a influências de modelos de gestão que, embora pautados em formas de participação social, se caracteriza autoritário e centralizador, isto em decorrência, por um lado, do conservadorismo político local, e, por outro, das influências de agências internacionais, como o Banco Mundial (BM), constantes do Programa de Apoio aos Secretários Municipais de Educação (PRASEM), promovido pelo MEC e adotado por esta localidade. Indica, ainda, a ausência de definições sobre as metas financeiras do PME em questão, para o autor, importante obstáculo à efetivação local desse plano.

Já na Região Sudeste, Villela $(2008,2009)$ se deteve nas concepções de cidadania dos atores envolvidos com o processo de elaboração do PME de Niterói, Estado do Rio de Janeiro, ocorrido no período 2003-2007. Assim, privilegiou, dentre outros dados coletados, a compreensão dos membros do CME desta cidade, envolvidos com as discussões em torno deste plano, especificamente no que remete à noção corrente sobre cidadania, constatando que para um grupo pode significar um estado acabado ou definitivo, enquanto que para outro algo que se encontra em permanente processo de construção.

\footnotetext{
16 Outros estudos relacionados ao Estado do Rio Grande do Sul, apesar de não elegerem o PME como objeto central de análise, sinalizam sua importância, por exemplo, para a construção local da cidadania, como no caso da pesquisa de Facco (2004), relativa ao Município de Fortaleza dos Valos.
} 
No âmbito da Região Centro-Oeste, identificou-se o estudo de Barboza (2008), cujo objetivo consistiu na análise da democratização da educação no Município de Dourados, Estado do Mato Grosso do Sul. O autor tomou por base o processo de participação da comunidade escolar (funcionários, pais, alunos, professores, coordenadores e diretores) na elaboração do PME, no período 2001-2004, consubstanciada no chamado Movimento Constituinte Escolar. Identifica, entre outros aspectos, que a ausência de uma tradição de diálogo entre a comunidade local e a esfera governamental e as dificuldades de coordenação enfrentadas pela equipe constituinte de mobilização da comunidade escolar vieram a comprometer o êxito do processo participativo da sociedade civil frente à elaboração do PME. O resultado foi um documento isento de objetivos e metas a serem cumpridas, "revelando as falhas deixadas pela Rede Municipal de Ensino, pelos participantes e pela própria Secretaria de Educação no que diz respeito ao entendimento sobre um Plano de Educação" (BARBOZA, 2008, p. 98).

No Nordeste, a pesquisa de Oliveira \& Aragão (2010) visou analisar o processo de elaboração e implementação do PME 2009-2019 de Arapiraca, Estado do Alagoas. O pressuposto em pauta era o planejamento como possibilidade democrática para 0 equacionamento dos problemas educacionais locais. Por sua vez, Souza (2006) objetivou analisar, em particular, a participação dos professores no encaminhamento de propostas relativas à elaboração do PME 2003-2013 de Assú, Estado do Rio Grande do Norte, no período 2003-2003.

No primeiro caso, Oliveira \& Aragão (2010, p. 7) afirmam que o PME de Arapiraca "é fruto de uma construção coletiva, onde os segmentos educacionais estaduais e municipais e a sociedade civil organizada" tiveram a oportunidade de discutir e traçar diretrizes e metas para a educação local, processo do qual essas autoras também participaram, tendo culminado numa política educacional que exprime "as reivindicações, os anseios da comunidade escolar e da sociedade civil" (ibidem, p. 10), em seguida afirmando que se trata de um plano "coberto de boas intenções e do envolvimento de todos os segmentos educacionais e sociais, apontando para uma experiência bem sucedida" (id.), em que pese reconhecer as limitações dos recursos destinados ao financiamento local da educação, de modo a contribuir para a melhoria da qualidade do ensino.

No segundo caso, Souza (2006) discute o PME de Assú, de um lado destacando a sua importância face ao planejamento estratégico local, tratando-o como potencialmente capaz de promover a articulação de forças deste Município em torno da democratização da educação, e, de outro, descrevendo o seu processo de construção com destaque para a participação do segmento docente, avaliando-o como bem sucedido. 
No cômputo geral, esses estudos trazem à vista a pluralidade de concepções e práticas denominadas participativas que marcam o(s) processo(s) de construção dos PMEs em algumas das localidades. As conclusões apresentadas reiteram uma possível tendência de ampliar e diversificar os atores que participam dos processos de elaboração dos PMEs. Isso tanto pode sinalizar a presença de políticas de gestão democrática e de participação sociopolítica na sua elaboração, quanto a manifestação do conservadorismo político local em torno das relações entre o poder público e a comunidade. De um modo ou de outro, pouco se continua sabendo a respeito da exequibilidade desses planos ou mesmo sobre 0 seu impacto local, já que, semelhante ao que ocorre com as poucas investigações relativas aos PEEs, as pesquisas sobre os PMEs se caracterizam, sobremaneira, pela preocupação em torno do caráter mais ou menos democrático do processo de construção desses planos, visando analisar o nível e grau da participação sociopolítica local, Registrou-se, ainda, a pouca inclinação para a análises propriamente ditas do conteúdo político-educacional deste instrumento, tampouco da avaliação da sua implementação local, e menos ainda dos efeitos alcançados à exceção, por exemplo, do estudo de Werle \& Barcellos (2008).

\section{Considerações finais}

Transcorridos 25 anos da promulgação da Constituição em vigor, assim como outros 17 anos relativos à nova LDBEN, e em que pese o quantitativo de planos de educação tanto em nível federal, quanto na esfera subnacional que estes marcos jurídicos vieram suscitar, ao que tudo indica, a gestão da Educação Básica ainda não logrou efetivamente democratizar-se no Brasil, o que coloca em questão, dentre outros aspectos, a pertinência e a exequibilidade do planejamento educacional levado a efeito nas últimas décadas, em especial as metas proclamadas.

Conforme revela a Pesquisa Nacional por Amostra de Domicílios (PNAD)/IBGE17, em 2011, ano previsto para iniciar a implementação de um novo PNE, o Brasil contava, ainda, com 12,9 milhões de pessoas acima dos 15 anos de idade que não sabiam ler ou escrever e o analfabetismo se concentrava na população acima de 30 anos de idade $(31,9 \%)$. Se a taxa de analfabetismo é descrente nos últimos 10 anos, o seu ritmo aponta para uma solução apenas a longo prazo. Na outra ponta da prestação dos serviços públicos que asseguram o direito à educação, verificou-se que o número de jovens de 15 a 17 anos

17 Disponível em: <http://www.ibge.gov.br/home/estatistica/populacao/trabalhoerendimento/pnad2011/>. Acesso em 23 ago. 2013. 
que frequentam a escola decresceu de 85,2\%, em 2009, para 83,7\% ${ }^{18}$, em 2011. Estancar essa nova tendência envolve planejamento no curtíssimo prazo mediante o diagnóstico das suas causas.

Esses resultados são sugestivos do processo da negação do direito à educação vivenciado no país e dos desafios a serem enfrentados. Por um lado, planejar 0 atendimento a uma expressiva parcela da população adulta excluída precocemente da escola mediante políticas mais robustas, capazes de intervenções que reduzam significativamente o contingente de analfabetos e analfabetos funcionais. Por outro lado, planejar a qualidade das escolas para a etapa final da Educação Básica, o Ensino Médio para jovens, de modo a tornar efetivo os princípios postos no art. 35 da LDBEN no 9394/1996

Acrescenta-se, ainda, o desafio de planejamento para a etapa da Educação Básica cujo atendimento é considerado como universalizado. De acordo com dados divulgados, em 2012, pelo movimento Todos pela Educação, cerca de 3,8 milhões de crianças e jovens de 4 a 17 anos se encontravam, em 2010, à margem da vida escolar, não obstante 0 aumento de 9,2\% dessa taxa de acesso, observada em relação aos 10 anos anteriores (BARBOSA, 2012). Em 2000, o censo demográfico IBGE apontava existência de 60\% da população sem o Ensino Fundamental completo, sendo que, nos dias atuais, identifica-se apenas a redução de 15 pontos percentuais nesta taxa, expondo ainda número elevado, pois quase a metade dos brasileiros (45\%) ainda não possui este nível de ensino completo (DUARTE; CASTRO; RIBEIRO, 2012). Esse atendimento se faz mediante a redução da taxa de distorção idade-série que passou de 23,3\%, em 2006, para 18,5\%, em 2010, isto para os anos iniciais do Ensino Fundamental, e de 35,4\% para 29,6\% para os anos finais desta mesma etapa da Educação Básica.

Dos que concluem o Ensino Fundamental, de acordo com os dados preliminares da Prova Brasil 2011, divulgados pelo Instituto Nacional de Estudos e Pesquisas Educacionais Anísio Teixeira (INEP)/MEC, em 2012, apenas 17\% o fazem com o domínio básico da matemática e $27 \%$ em língua portuguesa. Esses resultados registraram, ainda em 2011, a estagnação dos índices de proficiência no Ensino Médio em patamares similares aos de 2009 (GOIS; WEBER, 2010).

A configuração do atendimento no sistema educacional brasileiro, por sua vez, é sugestiva da importância de fundamentar o planejamento educacional com estratégia de combate a diversidade da exclusão educacional que se opera no país. Por um lado a

18 Esse percentual indica que 1,7 milhão de jovens, na faixa etária de escolaridade obrigatória, não estavam estudando em 2011. 
permanência de situações que o capitalismo do século XIX enfrentou e resolveu em muitos países, como o analfabetismo. Por outro lado, a saída precoce mitigadora do direito à educação com qualidade, presente em sociedades de desenvolvimento econômico subordinado, onde postos desqualificados de trabalho desqualificam demandas por prosseguimento nos estudos.

Resgatar a importância técnica e sociopolítica dos planos de educação nacional e subnacionais para o país consiste não apenas em propugnar a sua elaboração em bases democrático-participativas, mas observar a sua exequibilidade e pertinência em meio a um contexto marcado por ampla diversidade política e cultural, além de profunda desigualdade sócio-econômica.

Se por um lado, os poderes executivo e legislativo dos entes federados têm se furtado à elaboração ou aprovação de um plano nacional ou subnacional de educação por outro lado, a literatura a respeito reitera o descaso para com a democracia participativa nos processos de elaboração. O valor da gestão democrática é proclamado em diferentes ocasiões e espaços deste país, mas são também acompanhados por formas de gestão amadora, doméstica e casual, por isto mesmo isenta de transparência pública. Por sua vez, não implementar planos aprovados e tampouco acompanhá-lo acaba por adensar o desprezo não apenas pelo desenvolvimento da educação no país, mas, sobretudo, pela cidadania e justiça social.

Urge, portanto, que a sociedade civil cobre pelos PNE, PEEs, PREs e PMEs, assim como que os gestores da educação pública procedam, em conjunto com estes, à sua elaboração e implantação, e que os legisladores coloquem na ordem do dia a discussão e aprovação prioritária dos planos que ainda hibernam nas Câmaras Municipais, nas Assembléias Legislativas e, como péssimo exemplo para o país, no âmbito do próprio Congresso Nacional

\section{Referências Bibliográficas}

ABICALIL, Carlos Augusto. Plano Nacional de Educação na República Federativa do Brasil: instrumento de retórica ou política pública para a realização do direito à Educação Básica? Brasília, 2005. 185f. Dissertação (Mestrado em Educação) - Faculdade de Educação, Universidade de Brasília.

\section{7.}

PNE: limites e desafios; uma avaliação necessária. Brasília: Câmara dos Deputados,

AGUIAR, Márcia Ângela da Silva. Avaliação do Plano Nacional de Educação 2001-2009: questões para reflexão. Educação \& Sociedade, Campinas, v. 31, n. 112, 707-727, jul./set. 2010.

ARIAS, Valéria. A construção política do Plano Estadual de Educação (PEEPR) na gestão 2003-2006: controvérsias acerca do processo democrático no espectro do estado 
contemporâneo. Curitiba, 2007. 165 f. Dissertação (Mestrado em Educação) - Faculdade de Educação, Universidade Federal do Paraná.

ASSUMPÇÃO, Eracilda de. Plano Municipal de Educação: dá intenção à ação. In: WERLE, Flávia Obino Correa. (Org.). Sistema municipal de ensino e regime de colaboração. ljuí: Ed. Unijuí, 2006a, p. 137-154.

Planos Municipais de Educação: as interfaces da caminhada de construção. São Leopoldo, 2006b. 155 f. Dissertação (Mestrado em Educação) - Centro de Ciências Humanas, Universidade do Vale do Rio dos Sinos.

BARBOSA, Adauri Antunes. Quase 4 milhões fora da escola: estudo mostra que o Brasil não cumpriu meta de incluir crianças e jovens de 4 a 17 anos. $O$ Globo, 2. ed. Rio de Janeiro, 08 fev. 2012. Caderno O País, p. 3.

BARBOZA, Edir Neves. A constituinte em Dourados (2000-2004): um movimento em busca da democratização da Escola Pública. Dourados, 2008. 208 f. Dissertação (Mestrado em Educação) - Departamento de Educação, Fundação Universidade Federal do Mato Grosso do Sul.

BEISIEGEL, Celso de Rui. O Plano Nacional de Educação. Cadernos de Pesquisa, São Paulo, v. 29, n. 106, p. 217-231, mar. 1999.

BORDIGNON, Genuíno. Natureza dos conselhos de educação. João Pessoa: Secretaria da Educação e Cultura, 2001.

BRASIL. Câmara dos Deputados. Comissão especial destinada a proferir parecer ao Projeto de Lei n. 8.035, de 2010 - Plano Nacional de Educação: complementação de voto. Brasília: Câmara dos Deputados, 13 de jun. 2012.

BRASIL. Constituição (1988). Constituição da República Federativa do Brasil. Diário Oficial [da] República Federativa do Brasil, Brasília, 5 out. 1988.

Constituição (1988). Emenda Constitucional n. 15, de 12 de setembro de 1996. Modifica os artigos 34, 208, 211 e 212 da Constituição Federal e dá nova redação ao artigo 60 do Ato das Disposições Constitucionais Transitórias. Diário Oficial [da] República Federativa do Brasil, Brasília, 13 set. 1996a.

Constituição (1988). Emenda Constitucional n. 59, de 11 de novembro de 2009. Acrescenta $\S 3^{\circ}$ ao art. 76 do Ato das Disposições Constitucionais Transitórias para reduzir, anualmente, a partir do exercício de 2009, o percentual da Desvinculação das Receitas da União incidente sobre os recursos destinados à manutenção e desenvolvimento do ensino de que trata 0 art. 212 da Constituição Federal, dá nova redação aos incisos I e VII do art. 208, de forma a prever a obrigatoriedade do ensino de quatro a dezessete anos e ampliar a abrangência dos programas suplementares para todas as etapas da educação básica, e dá nova redação ao $\S 4^{\circ}$ do art. 211 e ao $\S 3^{\circ}$ do art. 212 e ao caput do art. 214 , com a inserção neste dispositivo de inciso Vl. Diário Oficial [da] República Federativa do Brasil, Brasília, 12 nov. 2009.

BRASIL. Instituto Brasileiro de Geografia e Estatística. Diretoria de Pesquisas. Coordenação de População e Indicadores Sociais. Perfil dos municípios brasileiros 2011. Rio de Janeiro: IBGE, 2012.

Perfil dos municípios brasileiros 2009. Rio de Janeiro: IBGE, 2010.

BRASIL. Lei n. 10.172, de 09 de janeiro de 2001. Aprova o Plano Nacional de Educação (PNE). Diário Oficial [da] República Federativa do Brasil, Brasília, 10 jan. 2001.

Lei n. 4.024, de 20 de dezembro de 1961. Fixa as diretrizes e bases da educação nacional. Diário Oficial [da] República Federativa do Brasil, Brasília, 27 dez. 1961.

Lei n. 5.692, de 11 de agosto de 1971. Fixa diretrizes e bases para o ensino de $1^{\circ}$ e $2^{\circ}$ graus, e dá outras providências. Diário Oficial [da] República Federativa do Brasil, Brasília, 12 ago. 1971. 
Lei n. 9.394, de 20 de dezembro de 1996. Estabelece as Diretrizes e Bases da Educação Nacional. Diário Oficial [da] República Federativa do Brasil, Brasília, 23 dez. 1996b.

BRASIL. Ministério da Educação. Secretaria Executiva. Documento final da CONAE. Brasília: MEC/CONAE, 27 maio 2010.

BRASIL. Projeto de Lei n. 8.035, de 20 de dezembro de 2010. Aprova o Plano Nacional de Educação para o decênio 2011-2020 e dá outras providências. Brasília, 20 dez. 2010 [Projeto de lei do governo federal, encaminhado ao Congresso Nacional em 20 de dezembro de 2010].

CALDERÓN, Adolfo Ignacio; SOUZA, Donaldo Bello de. CMEs nos estados de Santa Catarina e do Paraná: do pioneirismo ao lugar-comum das tendências hegemônicas. In: SOUZA, Donaldo Bello de (Org.). Mapa dos conselhos municipais de educação no Brasil. São Paulo: Loyola, 2013, p. 187-208.

CONFERÊNCIA MUNDIAL SOBRE EDUCAÇÃO PARA TODOS. Declaração Mundial sobre Educação para Todos: satisfação das necessidades básicas de aprendizagem - Jomtien, 1990. [s. I.], UNESCO, 1998.

CURY, Carlos Roberto Jamil. O Plano Nacional de Educação: duas formulações. Cadernos de Pesquisa, São Paulo, v. 28, n. 104, p. 162-180, jul. 1998.

Por um novo plano nacional de educação. Cadernos de Pesquisa, São Paulo, v. 41, n. 144, p. 790-811, 2011.

DANTAS, Gisele Kemp Galdino. Representações sociais sobre a escola pública paulista: do fórum "A Escola dos Nossos Sonhos" ao pesadelo do "Plano Estadual de Educação". Marília, 2008. 151 f. Dissertação (Mestrado em Educação) - Faculdade de Filosofia e Ciências, Universidade Estadual Paulista Júlio de Mesquita Filho.

DAVIES, Nicholas. Plano Nacional de Educação: muito discurso, nenhum recurso. Universidade \& Sociedade, São Paulo, v. 11, n. 25, p. 29-39, dez. 2001.

Plano Nacional de Educação: muito discurso, nenhum recurso. In: TEIXEIRA, Lúcia Helena G. (Org.). LDB e PNE: desdobramentos na política educacional brasileira. São Bernardo do Campo: Unesp, 2002. p. 117-143 (Cadernos Anpae, 1).

DE TOMMASI, Livia. Financiamento do Banco Mundial no setor educacional brasileiro: os projetos em fase de implementação In: DE TOMMASI, Livia; WARDE, Mirian Jorge; HADDAD, Sérgio (Orgs.). O Banco Mundial e as políticas educacionais. São Paulo: Cortez, PUC-SP, Ação Educativa, 1996, p. 195-227.

DRABACH, Neila Pedrotti; MIRANDA, Natália Pergher. Uma análise sobre a participação na construção do Plano Municipal de Educação de Santa Maria - RS. In: SIMPÓSIO BRASILEIRO DE POLÍTICA E ADMINISTRAÇÃO DA EDUCAÇÃO, 22., 2005, Rio de Janeiro. Anais... Rio de Janeiro: ANPAE, 2005. 1CD-ROM.

DUARTE, Alessandra; CASTRO, Juliana; RIBEIRO, Efrém. Para 45\%, ensino fundamental ainda é distante. O Globo, Rio de Janeiro, 28 abr. 2012. Caderno O País, p. 11.

DUARTE, Marisa Ribeiro Teixeira. Regulação sistêmica e política de financiamento da educação básica. Educação \& Sociedade, v. 26, n. 92, p. 821-39, 2005.

FACCO, Sandra Rubin. A educação para cidadania nas políticas públicas municipais: um Estudo do Plano Municipal de Educação de Fortaleza dos Valos/Rio Grande do Sul. ljuí, 2004. 201 f. Dissertação (Mestrado em Educação nas Ciências) - Instituto de Educação, Universidade Regional do Noroeste do Estado do Rio Grande do Sul.

FONSECA, Marília. O Banco Mundial como referência para a justiça social no terceiro mundo: evidências do caso brasileiro. Revista da Faculdade de Educação, v. 24, n. 01, p. 37-69, 1998 
GHENO, Eliane Terezinha. Políticas educacionais e processo de divulgação: o caso do Plano Municipal de Educação de Esteio. São Leopoldo, 2008. 148 f. Dissertação (Mestrado em Educação) - Centro de Ciências Humanas, Universidade do Vale do Rio dos Sinos.

GOIS, Antônio; WEBER, Demétrio. Só 17\% terminam o fundamental com domínio da matemática. O Globo, Rio de Janeiro, 03 nov. 2012. Caderno País, p. 6.

LACERDA, Alan Daniel Freire de. Ação coletiva e cooperação intermunicipal em duas metrópoles. Caderno CRH, Salvador. v. 24, n. 61, p. 153-166. 2011.

MARTINS, Paulo de Sena. Planejamento e plano nacional de educação. Cadernos Aslegis, Brasília, n. 39, p. 91-118, jan./abr. 2011.

MENDONÇA, Erasto Fortes. Plano Nacional de Educação: desdobramentos na política nacional. In: TEIXEIRA, Lúcia Helena G. (Org.). LDB e PNE: desdobramentos na política educacional brasileira. São Bernardo do Campo: UMESP, 2002. p. 13-54 (Cadernos Anpae, 1).

MUNARIM, Antonio. Educação e esfera pública na serra catarinense: a experiência política do plano regional de educação. São Carlos: UFSC, Centro de Ciências da Educação, Núcleo de Publicações, 2000.

Educação e esfera pública na serra catarinense: a experiência política do plano regional de educação. São Paulo, 1999, 357 f. Tese (Doutorado em Educação) - Faculdade de Educação, Pontifícia Universidade Católica de São Paulo.

OLIVEIRA, Cleiton de. Gestão da educação: União, Estado/Distrito Federal, município e escola. In: MACHADO, Lourdes Marcelino; FERREIRA, NauraSyriaCarapeto (Orgs.). Política e gestão da educação: dois olhares. Rio de Janeiro: DP\&A, 2002. p. 69-82.

OLIVEIRA, Maria José Houly Almeida de; ARAGÃO, Maria Helena de Melo. Plano Municipal de Educação - PME: a experiência do município de Arapiraca. In: COLÓQUIO INTERNACIONAL EDUCAÇÃO E CONTEMPORANEIDADE, 4., 2010. Laranjeiras. Anais...Laranjeiras: UFS. 11 p.

OLIVEIRA, Rosimar de Fátima. Revisando os mecanismos de formulação do Plano Nacional de Educação: considerações sobre o processo decisório. In: REUNIÃO ANUAL DA ASSOCIAÇÃO NACIONAL DE PÓS-GRADUAÇÃO E PESQUISA EM EDUCAÇÃO, 32., 2009, Caxambu. Anais... Rio de Janeiro: ANPEd, 2009.

PERONI, Vera Maria Vidal. Política educacional e papel do Estado. São Paulo: Xamã, 2003.

SANTOS, Ana Lúcia Ribeiro dos. Plano e gestão da educação municipal: relação entre proposta e efetivação. Curitiba, 2004a. 225f. Dissertação (Mestrado em Educação) - Faculdade de Educação, Universidade Federal do Paraná.

Plano e gestão da educação municipal: relação entre proposta e efetivação. In: SEMANA DE ENSINO, PESQUISA E EXTENSÃO DA UNIVERSIDADE FEDERAL DO PARANÁ, 18., Curitiba, 2004. Anais... Curitiba: Imprensa Universitária da Universidade Federal do Paraná, 2004b.

SAVIANI, Dermeval. Da nova LDB ao novo Plano Nacional de Educação: por uma outra política educacional. Campinas: Autores Associados, 1998.

Sistemas de ensino e planos de educação: o âmbito dos municípios. Educação \& Sociedade, Campinas, v. 20, n. 69, p. 119-136, dez. 1999.

SOUSA, Gustavo José Albino de. Planos nacionais, estaduais e municipais de Educação no Brasil: bibliografia comentada (1996-2010). Rio de Janeiro: NEPHEMFE/UERJ, 2012 (mimeo).

SOUZA, Donaldo Bello de; FARIA, Lia Ciomar Macedo de. O processo de construção da educação municipal pós-LDB 9.394/96: políticas de financiamento e gestão. In: Desafios da educação municipal. Rio de Janeiro: DP\&A, 2003. p. 45-84. (Org.). 
SOUZA, Donaldo Bello de; SOUSA, Gustavo José Albino de. Planos nacionais, estaduais e municipais de educação no Brasil: balanço quali-quantitativo sobre a literatura acadêmica (1996-2010). Agenda Social, Campos dos Goytacases, v. 6, p. 50-70, 2012.

SOUZA, Gustavo de Oliveira Coelho de; TORRES, Haroldo da Gama. O estudo da metrópole e o uso de informações georreferenciadas . São Paulo Perspectiva, São Paulo, v. 17, n. 3-4, p. 35-44, 2003.

SOUZA, Márcio Jocerlan de. Processo de elaboração do plano municipal de educação do Assú/RN e a participação dos professores. 2006. Natal, 142 f. Dissertação (Mestrado em Educação) - Centro de Educação, Universidade Federal do Rio Grande do Norte.

SOUZA, Somaya de Albuquerque. A complexidade do processo de democratização e de participação na elaboração do Plano Estadual de Educação de Alagoas. Maceió, 2007. 145 f. Dissertação (Mestrado em Educação) - Centro de Educação, Universidade Federal de Alagoas.

TEIXEIRA, Lúcia Helena G. Conselhos municipais de Educação: autonomia e democratização do ensino. Cadernos de Pesquisa, São Paulo, v. 34, n. 123, p. 691-708, set./dez. 2004.

TOMIO, Fabrício Ricardo de Limas. A criação de municípios após a constituição de 1988. Revista Brasileira de Ciências Sociais, São Paulo, v. 17, n. 48, p. 61-89, fev. 2002.

VALENTE, Ivan; ROMANO, Roberto. PNE: Plano Nacional de Educação ou carta de intenções? Educação \& Sociedade, Campinas, v. 23, n. 80, p. 96-107, set. 2002.

VALLE, Bertha de Borja Reis do; MENEZES, Janaina Specht da Silva; VASCONCELOS, Maria Celi Chaves. Plano Estadual de Educação do Rio de Janeiro: a trajetória de uma legislação. Rio de Janeiro: Quartet, 2012.

VIEIRA, Sofia Lerche; FARIAS, Isabel Maria Sabino de. Política educacional no Brasil: introdução histórica. Brasília: Líber Livro, 2007.

VILLELA, Viviane Merlim Moraes. O conceito de cidadania na definição de políticas públicas educacionais: debates e impasses no processo de elaboração do Plano Municipal de Educação de Niterói/RJ. Niterói, 2008. 245 f. Dissertação (Mestrado em Educação) - Faculdade de Educação, Universidade Federal Fluminense.

Responsabilização das esferas administrativas e constituição de planos municipais de educação: as diretrizes da política educacional do município de Niterói/RJ. In: SIMPÓSIO INTERNACIONAL - O ESTADO E AS POLÍTICAS EDUCACIONAIS NO TEMPO PRESENTE, 5., 2009, Uberlândia. Anais... Uberlândia: Universidade Federal de Uberlândia, 2009. [Obra indisponível na íntegra].

WERLE, Flávia Obino Corrêa; BARCELLOS, Jorge Alberto Soares. Plano Municipal de Educação e a afirmação de princípios para a educação local. Ensaio: Avaliação em Políticas Públicas em Educação, Rio de Janeiro, v. 16, n. 61, p. 515-542, out./dez. 2008. 